\title{
“Use Of Ender's Nailing in Treatment of Pediatric Fracture Shaft Femur"
}

\author{
Dr. N. Ravinder Kumar ${ }^{1}$, Dr. Vadlamani Kali Vara Prasad², Dr. M. Visvanath ${ }^{3}$, \\ Dr. R. Vamshi ${ }^{4}$ G.V.S. Murthy ${ }^{5}$. \\ ( $1 \& 2$ Associate Professors, $3 \& 4$ Senior Residents, 5 Professor Of Orthopedics. Department Of Orthopedics \\ \& Traumatology, Osmania Medical Collegel Hospital, Hyderabad, Telengana State.
}

\begin{abstract}
Background:Femoral shaft fractures account for $1.6 \%$ of all pediatric bony injuries..Fixation of femur fractures in children by ender's nailing is becoming widely accepted because of the lower chance of iatrogenic infection and cost. The objective of the study was to study the functional outcome,duration of union and the complications following the use of ender's nail for femoral shaft fractures in children and adolescents.

Material And Methods:Children between the age group of 5-16 years with femoral shaft fractures were admitted to osmania general hospital, afzal gunj, hyderabad in the period from october 2013 to october 2015.All patients underwent ender's nailing fixation for the sustained fracture.Patients were followed up between 3 months until 1 year after surgery. 20 cases were studied.

Results: Time for union was 8 weeks in 25\%,10 weeks in 45\%,12 weeks in $30 \%$.

Conclusion:Flexible intramedullary ender's nail leads to rapid fracture union by preservation of fracture hematoma and limited soft tissue exposure.It also helps in preventing damage to the distal femoral physis. Hence the conclusion is ender's

nailing is an excellent technique for the treatment of diaphyseal fractures of femur in children aged 5 to 16 years.

Keywords: Ender's nail,pediatric fracture shaft femur. For Correspondance : Dr. V.K.V. Prasad, Associate Professor, Department of Orthopedics \& Traumatology, Osmania Medical College, Hyderabad, Telengana State.
\end{abstract}

\section{Introduction}

Femoral shaft fractures account for $1.6 \%$ of all pediatric bony injuries ${ }^{1}$.There is little controversy over the treatment of adult femoral fractures with intramedullary nail fixation.similarly,there is little controversy over the treatment of infants and toddlerswith femoral shaft fractures by using spica casting ${ }^{2}$. But the treatment of pediatric femur fractures remains controversial..Current treatment options include early spica casting,traction,external fixation,ORIF with plating,flexible intramedullary nails and reamed intramedullary $\operatorname{rods}^{3}$.

In children, fractures of femoral shaft are commonly treated by various types of traction for about 3 weeks,followed by plaster cast immobilisation. The two major drawbacks with this treatment are prolonged bed rest and the expenditure. ${ }^{4}$...Angulation ,malrotation and shortening are not always corrected effectively ${ }^{5}$.The management of pediatric femoral shaft fractures gradually has evolved towards a more operative approach in the past decade.This is because of a more rapid recovery ${ }^{6}$.Plating of femoral shaft fractures offers rigid fixation.It requires a larger exposure with the potential for increased blood loss and scarring.It is a load bearing device and refracture is a risk.Antegrade nailing techniques have shown a risk of proximal femoral deformities and avascular necrosis of femoral head ${ }^{7,8,9}$ Elastic internal fixation in the form of ender's nailing provides a healthy environment for fracture healing with some motion leading to increased callus formation ${ }^{9}$.

Ender's nail fixation in the pediatric population is simple,effective and minimally invasive.It allows stable fixation,rapid healing and a prompt return of child to normal activity.Functional results are excellent and complications are minor ${ }^{9}$.

\section{Aims And Objectives Of The Study}

1. To study the functional outcome following the use of ender's nails for femoral shaft fractures in children.

2. To study the duration of union in the above mentioned fractures.

3. To study the complications of ender's nailing of femoral shaft fracture 


\section{Materials And Methods}

In this study 20 patients, aged 5 to 16 years, with fracture shaft of the femur were treated with retrograde ender's nailing at Osmania General Hospital attached to Osmania Medical College in the period from October 2013 to October 2015

\section{Method of data collection:}

The study includes patients with Femoral shaft fractures admitted and examined according to protocol. Associated injuries were noted. Clinical and radiological investigations were carried out and medical fitness for surgery to undergo ender's nailing fixation for the sustained fracture was taken. Patients were followed up at 1,2,3,6 months intervals till fracture union and once at 1 year after surgery.

A minimum of 20 cases were studied without any sampling procedure .

\section{Inclusion criteria:}

- Children \& adolescent patients between 5 to 16 years of age

- Stable femoral shaft fractures

- $\quad$ Type I and II compound fractures

\section{Exclusion criteria:}

- Patients aged less than 5 years and more than 16 years of age

- Patients medically unfit for surgery

- Comminuted and segmental fractures

- Type III Compound fractures

- Very distal (or) very proximal fractures that precludes nail insertion.

\section{Results}

Age Distribution

\begin{tabular}{|l|l|l|}
\hline Age in years & No. of cases & Percentage \\
\hline $6-8$ & 6 & 30 \\
\hline $9-12$ & 10 & 50 \\
\hline $13-16$ & 4 & 20 \\
\hline
\end{tabular}

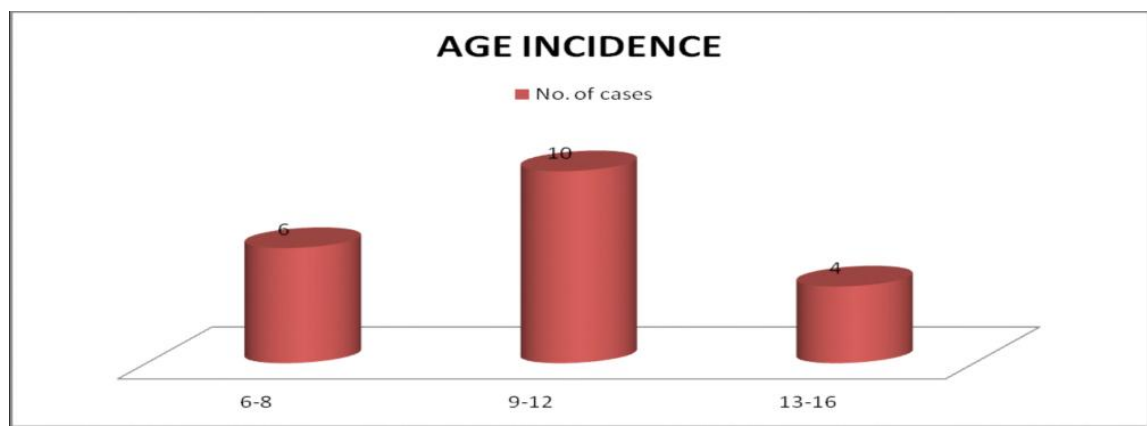

Table 2 : Sex incidence

\begin{tabular}{|l|l|l|}
\hline Sex & No.of cases & percentage \\
\hline Male & 14 & 70 \\
\hline Female & 6 & 30 \\
\hline
\end{tabular}

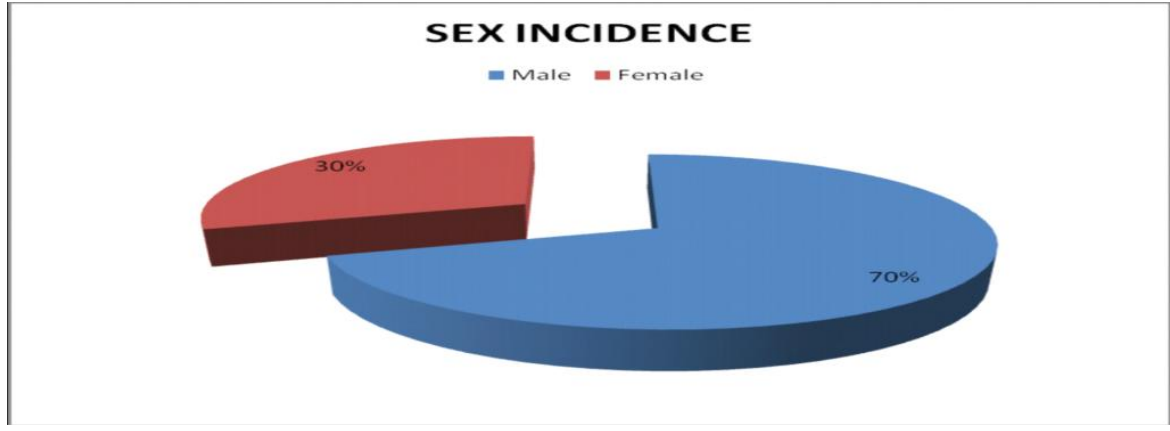


Table 3 : Nature of trauma

\begin{tabular}{|l|l|l|}
\hline Nature of rrauma & no.of cases & percentage \\
\hline RTA & 11 & 15 \\
\hline Fall while playing & 1 & 5 \\
\hline Fall from height & 8 & 40 \\
\hline
\end{tabular}

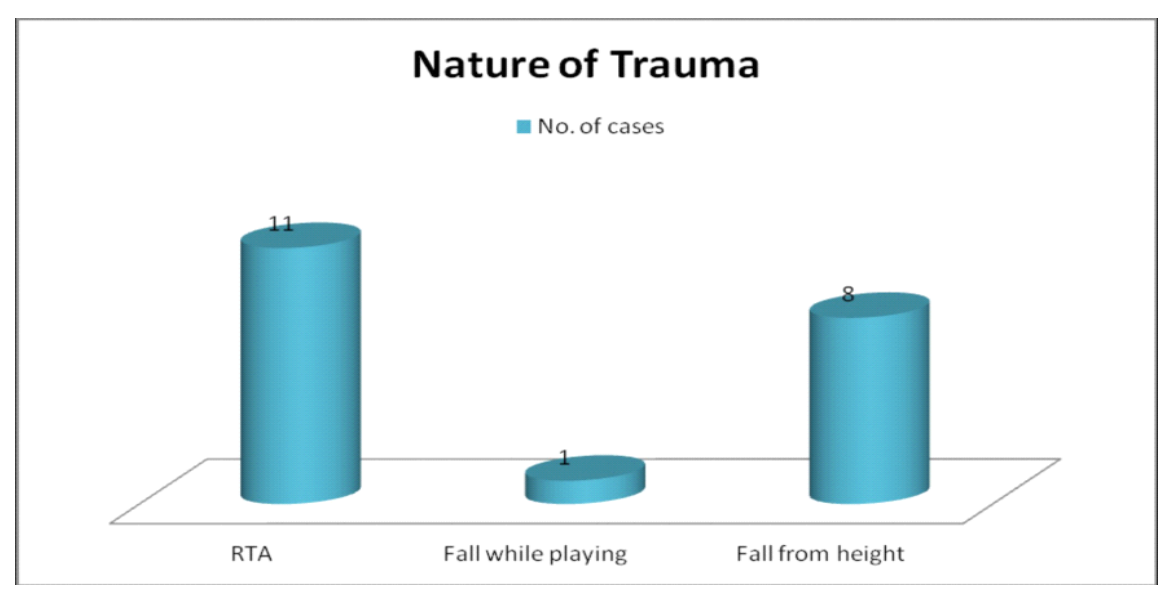

Table 4 : Side affected

\begin{tabular}{|l|l|l|}
\hline Side affected & No.of cases & percentage \\
\hline Left & 7 & 35 \\
\hline Right & 13 & 65 \\
\hline
\end{tabular}

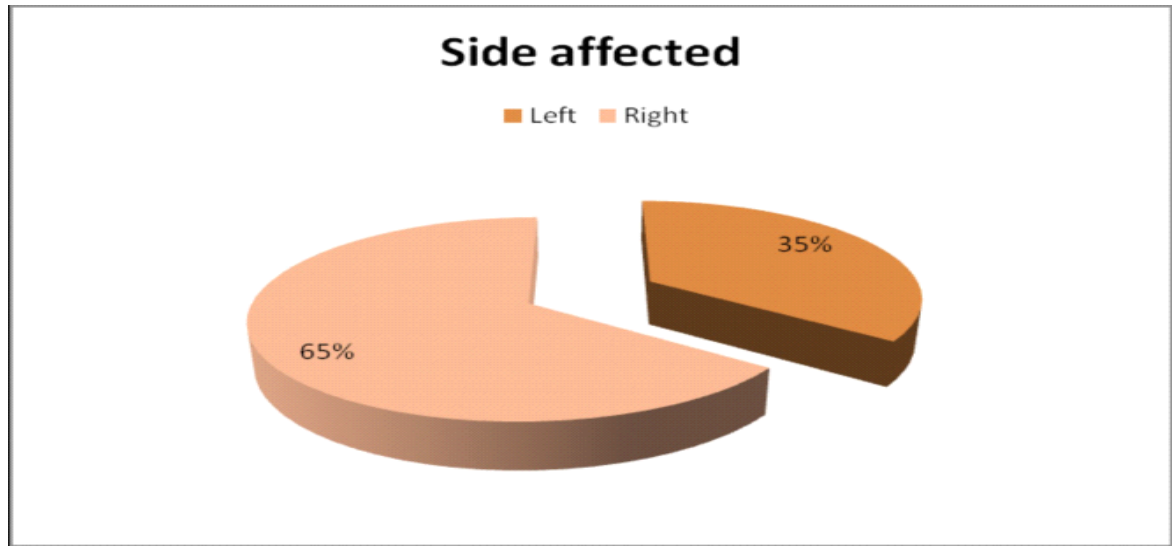

Table 5 : Pattern of Fracture

\begin{tabular}{|l|l|l|}
\hline Pattern of fracture & no.of cases & percentage \\
\hline Transverse & 13 & 75 \\
\hline Oblique & 3 & 15 \\
\hline Spiral & 4 & 20 \\
\hline
\end{tabular}

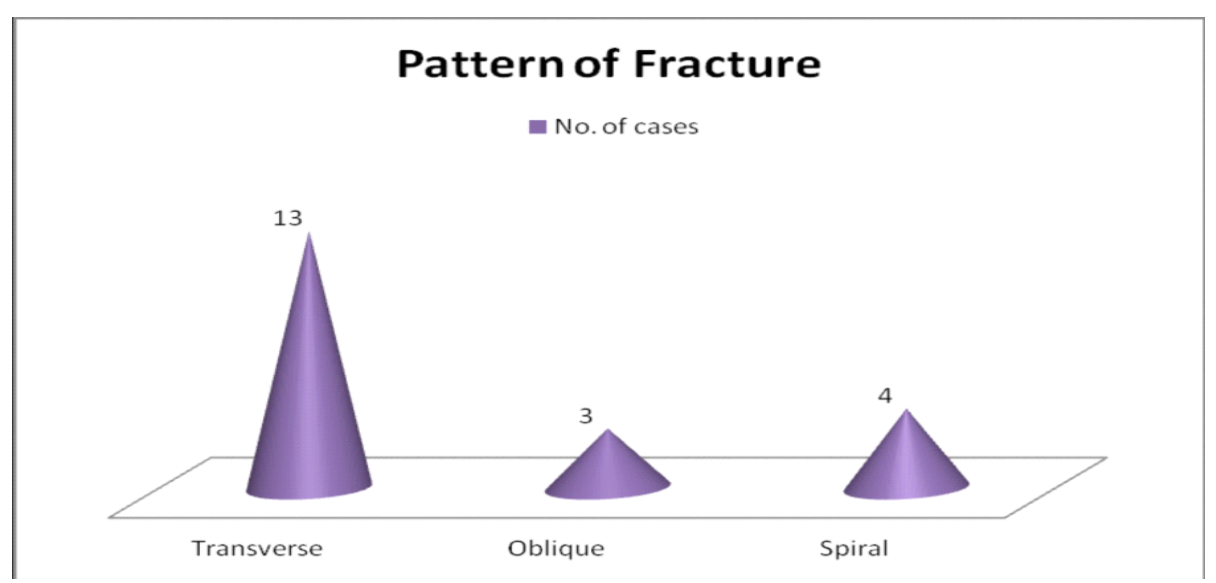


Table 6: Level of the Fracture

\begin{tabular}{|l|l|l|}
\hline Level of fracture & no.of cases & percentage \\
\hline Proximal & 3 & 15 \\
\hline Middle & 17 & 85 \\
\hline
\end{tabular}

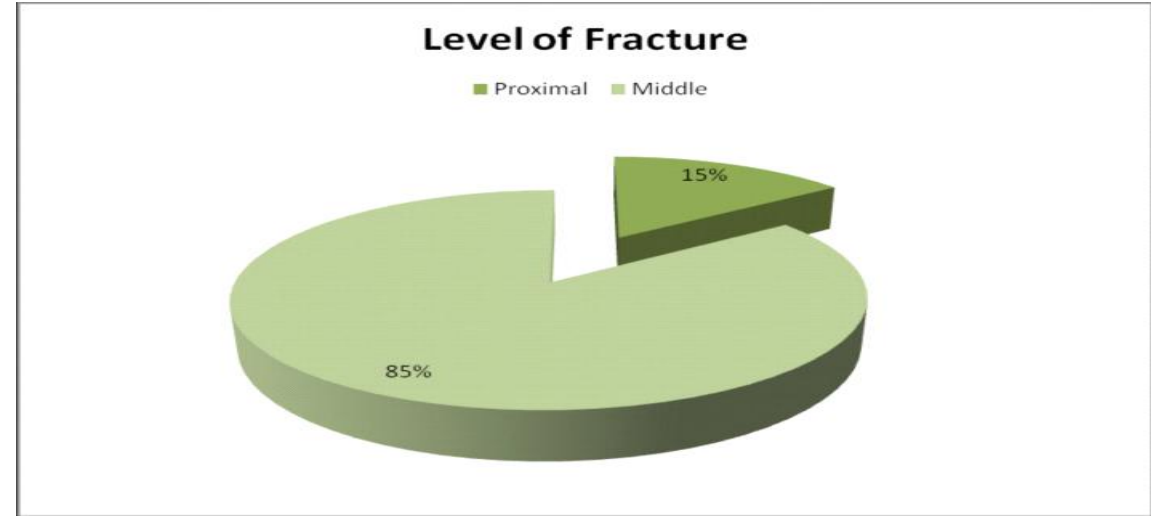

Table 7: Type of Fracture

\begin{tabular}{|l|l|l|}
\hline Type pf fracture & no.of cases & percentage \\
\hline Closed & 18 & 90 \\
\hline Open & 2 & 10 \\
\hline
\end{tabular}

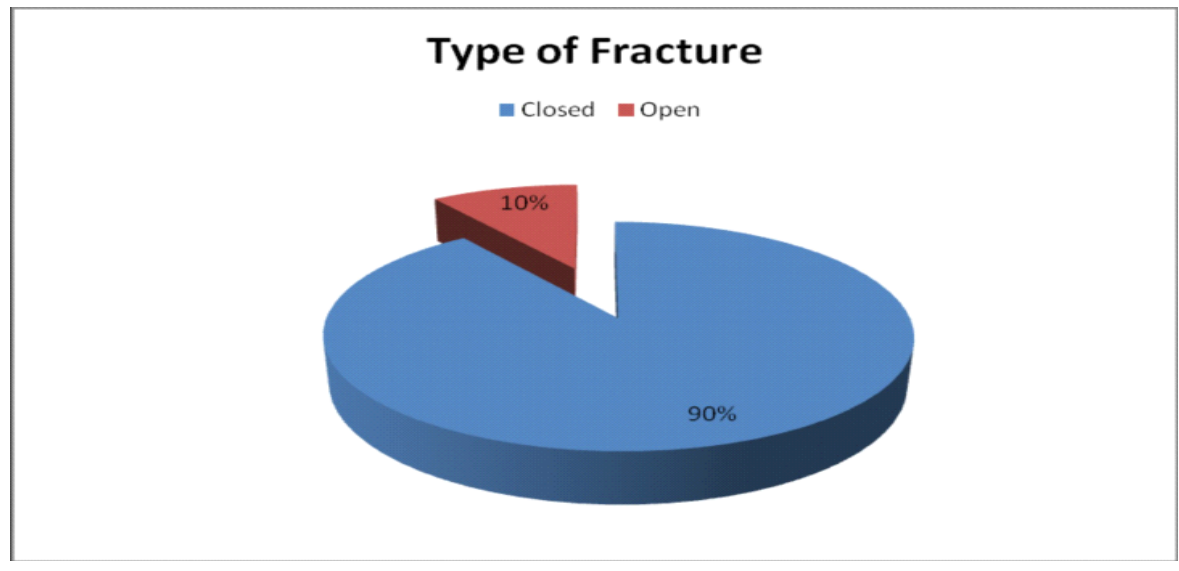

Table 8: Time interval between trauma and surgery

\begin{tabular}{|l|l|l|}
\hline Duration in days & no.of cases & percentage \\
\hline$<24$ hrs & 3 & 15 \\
\hline $2-4$ days & 14 & 70 \\
\hline $5-7$ days & 1 & 5 \\
\hline$>7$ days & 2 & 10 \\
\hline
\end{tabular}

\section{Time interval between Trauma and Surgery}

No. of cases

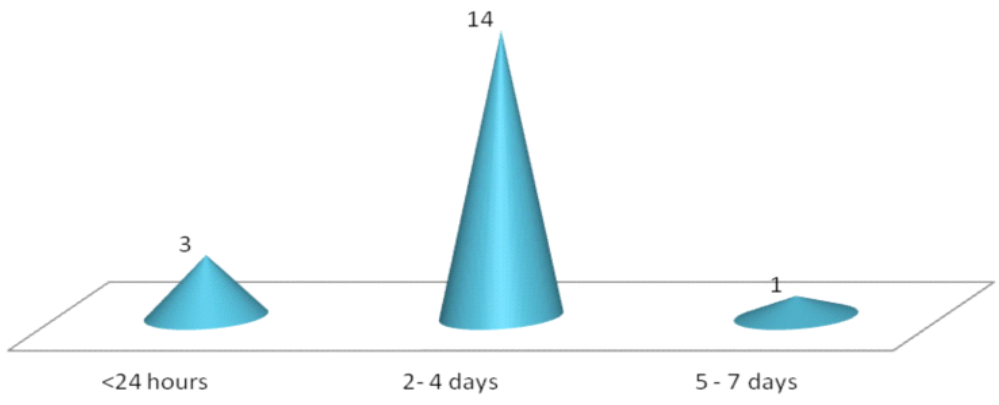


Table 9: Type of Reduction

\begin{tabular}{|l|l|l|}
\hline Reduction & no.of cases & percentage \\
\hline Closed & 16 & 80 \\
\hline Open & 4 & 20 \\
\hline
\end{tabular}

Table 10 : Size of nail

\begin{tabular}{|l|l|l|}
\hline Size of nail & no.of cases & percentage \\
\hline $2 \mathrm{~mm}$ & 1 & 5 \\
\hline $2.5 \mathrm{~mm}$ & 10 & 50 \\
\hline $3 \mathrm{~mm}$ & 7 & 35 \\
\hline $3.5 \mathrm{~mm}$ & 2 & 10 \\
\hline
\end{tabular}

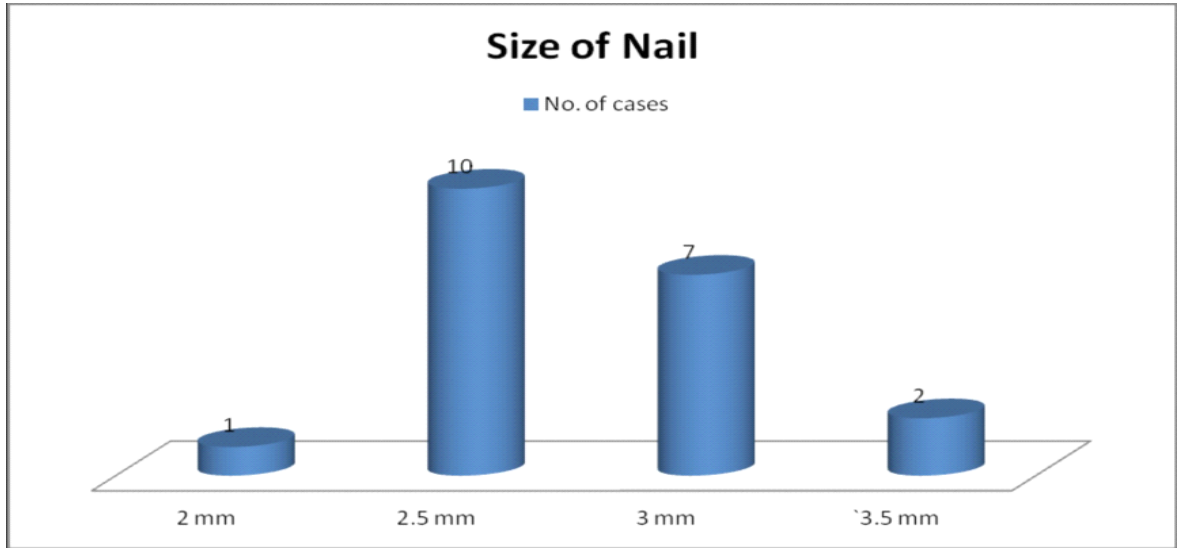

Table 11 : Stay in Hospital

\begin{tabular}{|l|l|l|}
\hline $\mathrm{r}$ & no.of days & percentage \\
\hline $6-9$ & 1 & 5 \\
\hline $10-12$ & 16 & 80 \\
\hline$>12$ & 3 & 15 \\
\hline
\end{tabular}

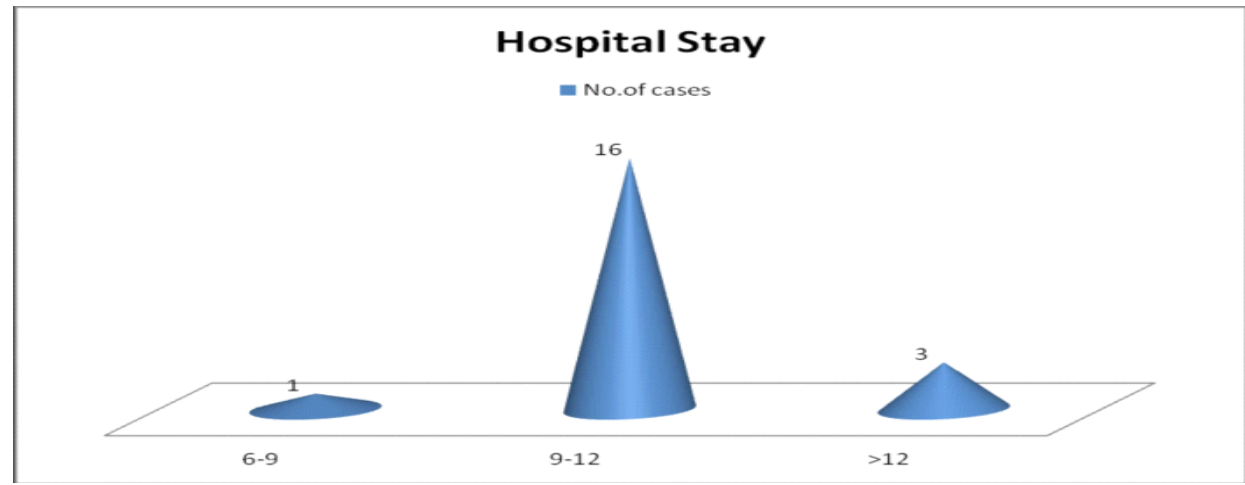

Table 12: Time for union

\begin{tabular}{|l|l|l|}
\hline Time for union & no.of cases & percentage \\
\hline 8 weeks & 5 & 25 \\
\hline 10 weeks & 9 & 45 \\
\hline 12 weeks & 6 & 30 \\
\hline
\end{tabular}

\section{Operative Procedure}

General anaesthesia was used in younger children and spinal anaesthesia was used in older children and adolescents. supine position.

. The image intensifier is used to localize the placement of skin incisions by viewing the distal femur in the AP and lateral planes. The level of the insertion of flexible nail should be 2.5 to $3 \mathrm{~cm}$ proximal to the distal femoral physis in the AP view and it should be in the middle of the cortex in the lateral view. Incision of about 2 to $3 \mathrm{~cm}$ is put on both medial and lateral aspects of the thigh at the site of insertion of the nail. Soft tissue was split and the bone was exposed on both sides. A hole was made in the cortex by using $4.5 \mathrm{~cm}$ drill bit and then a bone awl was used to widen the cortical hole in the bone. The awl is then inclined 10o anteriorly and steeply angled in the frontal plane to facilitate passage of the nail through the dense paediatric metaphyseal bone. 
Rod bending:

A gentle 300 bend was placed in the nail with the apex at what will be the level of the fractures.

\section{Postoperative Care:}

- Patients were kept nil orally 4 to 6 hours post operatively.

- IV fluids /blood were given as needed.

- IV antibiotics were continued.

- Analgesics and tranquilizers were given according to the needs of the patient.

- $\quad$ Foot end of the bed was elevated.

IV antibiotics were continued for 5 days and switched over to oral antibiotics on the 5 th day and continued till the 10th day. Quadriceps strengthening and active assisted range of motion exercises were began immediately. Knee bending exercises were started according to the patient's pain tolerance. The patients were mobilized with a walker on the morning after operation, with non weight bearing on the affected limb. Sutures were removed on the 10th postoperative day and patients were discharged and adviced non weight bearing.

Further follow ups were done at 1 month , 2 month,3 months, 6 months and 1 year. Each patient was individually assessed clinically and radiographically. Observations were made regarding the alignment of the fracture, the range of motion of knee and hip, limb length discrepancy, degree of pain or swelling and rotational deformity of the femur. Rotational deformities were measured by using foot progression angle.

\section{Complications: \\ Range of motion:}

All patients had full range of hip motion in the present study, 3(15\%) patients had 10 degree restriction of knee movements (flexion) which was corrected by rigrous physiotherapy, while 1 (5\%) patients had terminal 450 restriction in knee flexion at 2 months, but normal range of knee flexion was achieved at six months. Loss of motion at the knee was seen in $14(53.84 \%)$ patients in Herscovici et al ${ }^{10}$ study.

Bar- On E, et al ${ }^{11}$ noted 20 o loss of internal rotation at the hip in one patient treated with external fixation. Flynn $\mathrm{J}$ M et al ${ }^{12}$ noted one case of knee stiffness in patients treated with spica casting which required manipulation under anaesthesia.

\section{Limb length discrepancy:}

This is the most commom complication, Fabiano Prata Nascimento et al ${ }^{13}$ showed the final shortening on the limb, after a follow-up period of at least 24 months, occurred in $6.7 \%$ of the cases (two patients), with $0.25 \mathrm{~cm}$ on average. Mazda K et al ${ }^{14}$ noted limb length discrepancy of more than $10 \mathrm{~mm}$ in $3(8 \%) \mathrm{o}$ fcases. Herndon WA, et al ${ }^{15}$ noticed limb length shortening ranging from 1 to $4.6 \mathrm{~cm}$ in 7 patinets. Comparing to limb length discrepancy in conservative methods, limb length discrepancy in our study was within the acceptable limits.

\section{Infection:}

Superficial infection was seen in 3 cases in our study which was controlled by antibiotics. Pin tract infection is a major disadvantage of external fixation application. Bar-on E, et al ${ }^{11}$ reported 2 cases of deep pin tract infection in their patients treated with external fixation. Blasier RD, et al, Davis TJ, et al and Fein LH, et al observed that the risk of pin tract infection ranges from $36 \%$ to $62 \%$ and the risk of refracture or fracture through a pin tract ranges from $0 \%$ to $36 \%$. Alenjandro uribe Rios et al ${ }^{16}$ observed that there were two cases of superficial infection which were treated with oral antibiotics with no subsequent hospitalization, and without their final results being affected.

\section{Nail impingement at insertion site:}

In the patient series, nail impingement was seen in $3(15 \%)$ patient. In the study conducted by Fabiano Prata Nascimento et al ${ }^{13}$ acute complications were seen in two patients $(6.7 \%)$. One had a migration of a nail and the other had a soft tissue irritation. The first patient needed a second intervention in order to have the tip of the nail cut. One felt pain during the first week postoperatively and needed another surgery to correct the loss of reduction of the fracture.

In the study conducted by Alejandro et al, ${ }^{16}$ seven (14\%) cases of inflammation were observed at the insertion site because the nails were inserted within a cortical superior to the one suggested by the surgical technique, six of those cases occurred in the medial approach; and five required early reoperation ( 2 week ) because of imminent skin injury. 


\section{Malalignment:}

Some degree of angular deformity is frequent after femoral shaft fractures in children, but this usually remodels after growth.

\section{Varus/valgus malalignment:}

In our study there was no varus/valgus malalignment. Heinrich SD, et al reported 5oof varus angulation in one child in their study and $11 \%$ of fractures had an average varus or valgus malalignment of 6o. John Ferguson MB, et al ${ }^{14}$ noticed $7 \mathrm{o}$ varus angulation in one patient in their study.

Herndon WA, et al ${ }^{15}$ compared the results of femoral shaft fractures by spica casting and intramedulllary nailing in adolescents. They noticed varus angulation ranging from 7 to 250 in 4 patients treated with spica casting and no varus angulation in surgical group. Herndon WA, et al ${ }^{15}$ noticed 120 valgus angulation in one patient treated with spica casting.

Alenjandro uribe Rios et al ${ }^{16}$ observed two angular deformities in the valgus. Fabiano Prata Nascimento et al ${ }^{13}$ noticed valgus in $12(40 \%)$ and varus in $3(10 \%)$ patients. The varus and valgus malalignment that occurred in our study are within the acceptable limits.

\section{Antero posterior angulations:}

In the patient study, there were no antero posterior angulation. Anteroposterior angulation ranged from 5.6o to 7.60 in children treated with immediate spica casting in infante AF, et al ${ }^{17}$ study. Ozturkman Y, et al ${ }^{18}$ noted an anterior angulation of $7 \mathrm{o}$ and a posterior angulation of 60 in 2 patients respectively. Herndon WA, et al ${ }^{15}$ noticed anterior angulation ranging from 80 to 350 inpatients treated with traction and spica casting. 8\% of the patients had an average anterior or posterior angulation of 80 in Heinrich SD, et al 6 study. Bar-on E, et al ${ }^{11}$ noticed one case of posterior angulation treated by external fixation. Fabiano Prata Nascimento et al ${ }^{13}$ noticed $23(76.7 \%)$ anterior angulation and $5(16.6 \%)$ posterior angulation.

\section{Rotational deformities :}

A difference of more than 10o has been the criterion of significant deformity. In toeing or out toeing was not reported in our study. Heinrich SD, et al ${ }^{5}$ reported out toeing in 4 children with an average of 60 and two children with 7.50 of in toeing following flexible intramedullary nailing. No patient in our study had significant rotational deformity.

\section{Other complication:}

In our study no proximal migration of nails was seen in any of the cases. Bar-on E, et al ${ }^{11}$ noticed proximal migration of the nail in one case. Kregor PJ, et al ${ }^{19}$ reported $13 \mathrm{o}$ anterior angulation in one case and overgrowth of the injured femur averaging $0.9 \mathrm{~cm}$ in patients treated with compression plate fixation. Ward et al ${ }^{20}$ managed 24 children between the ages of 6 and 16 years old with $4.5 \mathrm{~cm}$ DCP. Six patients had a limb length discrepancy of $1 \mathrm{~cm}$ or more. One patient had bending of the plate and another had a stress fracture after the late was removed. The advantages of the present study include minimal scarring, closed reduction, load sharing device, fracture heals by secondary callus formation which is more stronger and refracture is not a risk.

Rigid intramedullary nailing is also described in the management of femoral shaft fractures. Raney EM, et al ${ }^{21}$ noticed premature closure of the greatertrochanteric physisi consequent to intramedullary nailing.

\section{Conclusion}

- $\square$ Flexible intramedullary nail introduction is easier. It provides stable fixation.

- $\square$ It is an excellent mode of treatment for simple transverse and obliquefractures of femoral shaft.

- $\square$ Closed intramedullary nailing is an efficient method and does not expose the patient to an undue risk of infection or non union

- $\quad \square$ Flexible intramedullary nailing leads to rapid union by means of preservation of the fracture haematoma and limited soft tissue exposure.

- $\square$ It appreciably reduces the length of the hospital stay and eliminates the need for prolonged rest in bed by providing early independent ambulation.

- Thus it reduces the morbidity and dependency of the patients.

\section{References}

[1]. Scherl SA Miller L, Lively N, Russionof S, Sullivan M Tornetta P III. Etal. "Accidental and non accidental femur fractures in children". Clin Orthopand Rel Research 2000;376:96-105.

[2]. Momberger N., Stevens P., Smith J., Santora S, Scott S and AndersonJ. "intramedullary nailing of femoral fractures in adolescents". J PediatrOrthop 2000; Vol. 20:482-484.

[3]. Lee SS, Mahar AT and Neton PO. "Ender nail fixation of pediatrics femurfractures. Abiomechanical analysis". J Pediatr Orthop 2001; Vol. 21: 442-445. 
[4]. Ligier JN ., Metaizeau JP., Prevot J. and Lascombes P. "Elastic stableintramedullary nailing of femur shaft fracture in children". J Bone \& JointSurg (Br) 1988; Vol 70B 74-7.

[5]. Heinrich SD., Drvaric DM., Karr K. and Macevan GD. "The operativestabilization of pediatric diaphyseal femur fracture with flexibeintramedullary nails: A prospective analysis". J Pediatr Orthop 1994; Vol.14: 501-507.

[6]. Carey TP. And Galpin RD. "Flexible intramedullary nail fixation of femoralfractures". Clin Orthop and Rel Research 1966; 332:110-118.

[7]. Cramer KE., Tornetta P. III, Spero CR, Alter S, Miraliakber H, Teefey J. "Enter rod fixation of femoral shaft fracture in children". Clin Orthop and Rel Research 2000;376:119-123.

[8]. Townsend DR and Hoffinger S. "Intramedullary nailing of femoral shaft fractures in children via the trochanteric tip". Slin Orthop and Rel Research 2000;376:113-118.

[9]. Kasser JR. and Beaty JH. “Fem,oral shaft fractures”. In: Beaty JH. And Kasser JR eds. Rockwood and Wilkins, 2001;941-980pp.

[10]. 10.. Herscovici D, Scott DM, Behrens F et al. The use of Ender nails in femoral shaft fractures : what are the remain- ing indications ? J Pediatr Orthop $1992 ; 6: 314-317$.

[11]. Bar- on E, Sagiv S. and Porat S. "External fixation or flexible intramedullary nailing for femoral shaft fractures in children". J Bone and Joint Surg (Br) 1997;79-B: 975-8.

[12]. Flynn JM Met al,luedtke LM,Ganley TJ.et al."comparision of titanium elastic nails with traction and a spica cast to treat femoral fractures in children".Bone and joint surg 2004; vol.86-A(4):770-7.

[13]. Fabiano Prata Nascimento,claudio santili,miguel akkari gilberto waisberg,susana dos Reis braga,Patricia Maria Moraes de Barros Fucs.short hospitalisation period with elastic stable intramedullary nails in the treatment of femoral shaft fractures in school children.J Child Orthop 2010;4:53-60

[14]. Ferguson J. and Nicol Ro." Early spica treatment of pediatric femoral shaft fractures".J Pediatr.orthop 200;20:189-92.

[15]. Herndon WA.,Mahnken RF.,Yngve DA.and Sullivan JA."Management of femoral shaft fractures in the adolescent".J pediatr Orthop 1989;9(1):29-32.

[16]. Alenjandro Uribe Rios,Diego fernandoSanm Arango.Carlos Oliver Valderamma Molina and Alvaro de Jesus Toro Posada.'Femoral shaft fracture with stainless steel flexible nails in children aged between 5 and 12 yrs at the HUSVP.J Child Orthop 2009 3:129-135.

[17]. Infante AF.Jr. Albert MC,Jennings WB.and Lehner JJ.'Immediate hipspica casting for femur fracture in pediatric pateints.A review of 175 patients".clin Orthop and Rel Reseacg 2000;376:106-112.

[18]. Ozturkman Y.Dorgul c,Balioglu MB. And Karli M.’'Intramedullary stabilisation of pediatirc diaphyseal femur fracture with elastic nails".Acta Orthop Traumatol Jure 2002;36(3):220-7.

[19]. kregor PJ.,Song KM.,Chip Routt ML.,Jr.,Sangeorzan BJ.,liddell RM and Hansen ST.Jr.’Plate fixation of femoral shaft fractures in multiply injured children".J Bone and Joint Surg 1993;75A(12):1774-80.

[20]. Ward WJ.,Levy J and Kaye A.”Compression plating for child and adolescent femur fractures".J Pediatr Orthop 1992:12:626-632.

[21]. Raney Em.,Ogden JA and Grogen DP.’Premature greater trochantericepiphysiodesis secondary to intramedullary femoral rodding”J pediatrOrthop 1993;13:516-520. 